\title{
Spatial Structure of Housing Prices in Nanchang, China
}

\author{
Liting Xu, Yeqiao Wang*, Yu Xu, Yu Zhou and Zengzheng Wang \\ Key laboratory of Poyang Lake Wetland and Watershed Research, Ministry of Education, School of Geography and Environment, \\ Jiangxi Normal University, Nanchang, Jiangxi, China \\ *Corresponding author
}

\begin{abstract}
Spatial variation of housing prices is an important contents of urban geography studies. Most efforts have studied space structure of residential district in big cities. The aim of this study was to apply it in a medium-sized city, Nanchang. Spatial autocorrelations analysis and Kriging interpolation method were used to explore the spatial distribution of residential district. Residential district data were based on 808 residential districts collected from two real estate websites at June 2015. In this transverse study, housing prices shows significant positive spatial correlation with significant characteristics of "shortcut" and "hydrophilic". Moreover, the spatial distribution of housing prices is unbalanced, which shows the feature of one major center and multiple sub-centers. Future research may benefit from additional longitudinal studies to confirm these findings.
\end{abstract}

\section{Keywords-residential district; housing prices; spatial pattern}

\section{INTRODUCTION}

Housing reform was put on the agenda as soon as the Chinese government launched its economic reform in 1979 [1]. Today China has transformed from a centrally planned public housing system to a market-oriented housing industry. The urban housing system reform promoted the free flow of urban residents and allowed them to buy house independently based on financial situation and preferences, which led to rapid separation of urban residents in social space and reshaped urban social space structure [2]. Housing prices is the major concerns of house choice; it's a reflection of residential location, quality, and environment [3].

Residential district is a vitally and widely used urban land utilization type, which affects urban spatial morphology. Housing prices are combined effect of location, land price, environment, architectural quality and other factors. Identifying the housing prices spatial variation has been the subject of studies. So far researches mainly focused on hedonic house price method and Geographic Information Systems (GIS) technology [4]. T. Ogwang and his colleagues used hedonic price function estimated the characteristics of residential houses in Prince George [5]. J. C. Olmo has estimated housing location prices according to location, obtain interpolated maps by kriging and cokriging methods [6]. A. G. Can used GIS technology in housing and mortgage market research [7]. With the implementation of urban housing system reform, urban residential space differentiation phenomenon is highlighted gradually in China. Some scholars studied the differentiation theory of residential spatial structure, summarized the progress and trends of residential spatial differentiation research [8].
Some used hedonic model analyzed influencing factors of housing prices [9]. Others used GIS technology study the spatial differentiation of regional housing prices [10]. Research areas were concentrated in Beijing, Shanghai, Guangzhou, Nanjing, Xi'an, Changsha, Ji'nan and some other big cities. There are few studies on small and medium-sized cities.

Ordinary commercial houses can reflect spatial distribution of housing prices well because of their characteristics of big transactions market, wide spatial distribution, relatively transparent information and so on [11]. GIS technology offers an ideal research environment for processing, analyzing, and modeling housing and mortgage data sets [12]. Spatial autocorrelation refers to the potential interdependence between some variables in the same distribution area, it can determine whether there is a spatial structure relationship between regional variations or not, and help identify the spatial differentiation and clustering. Spatial autocorrelation including global spatial autocorrelation and local spatial autocorrelation. The Global spatial autocorrelation describe the spatial characteristics of attribute values in the whole region, it test adjacent space or similar area unit's attribute values in the overall trend of the spatial correlation in the study area [13,14].

The case study of this paper is the main city of Nanchang, the capital of Jiangxi province, a second-tier cities in the central region of China. Taking intensive distribution housing areas of Nanchang as study area based on "Nanchang City Master Plan (2003-2020)", the ordinary commercial residential area were taken as the research object considering because of its big market transactions volume and high occupancy rate. We used the relevant statistical methods and GIS spatial analysis method to explore the distribution pattern of housing prices of residential area and its influencing factors in Nanchang City.

\section{MATERIALS AND METHODS}

\section{A. Database on Housing Price}

Data of residential district constructed from 2000 to 2014 were collected at June 2015 from two real estate websites (http://nc.fang.com/ and http://nc.anjuke.com/). Average price, location, construction year and other information were collected and geocoded each residential district sample though Baidu map API. The price data is the average sale price of real estate for their representativeness in the overall housing prices level among the area [15]. We got 808 residential district samples after eliminate samples with incomplete information; all data of residential district were put in EXCEL table. Then 
we imported them into ArcGIS, automatically generated the spatial distribution layer of residential district through its latitude and longitude properties. We normalized the average prices of residential district by logarithm transformation. Then we collected the study boundary, road and water area data from the comprehensive transportation planning map in the "Nanchang City Master Plan (2003-2020)". They were vectorized in ArcGIS, and integrated with residential district data. Thus we got the space distribution evolution figure of Nanchang residential district.

\section{B. Buffer Analysis}

We used buffer analysis to explore the influence of traffic and water area to housing prices. After we set up a complete database. A 0.5 kilometers buffer zone around some major traffic routes and a 1 kilometers buffer zone around the subway line 1 , as well as a 1 kilometers buffer zone around some water area were conducted. Buffer zone and residential district samples were integrated together. There are 678 residential district samples within the major traffic line buffer, accounting for $83.91 \%$ of total samples, 293 samples within subway buffer, accounting for $36.26 \%$ of total samples, and 360 residential district samples within water buffer, accounting for $44.55 \%$ of total samples.

\section{Spatial Autocorrelation Analysis of Housing Prices in Nanchang}

The Global Moran's I index was applied to inspect spatial autocorrelation, it is an effective method of spatial analysis which can determine whether there is a phenomenon of agglomeration in space or not. The equation as follow:

$$
\text { Moran's } I=\frac{\sum_{i=1}^{n} \sum_{j=1}^{n} W_{i j}\left(X_{i}-\bar{X}\right)\left(X_{j}-\bar{X}\right)}{\sum_{i=1}^{n}\left(X_{i}-\bar{X}\right) / n \sum_{i=1}^{n} \sum_{j=1}^{n} W_{i j}}
$$

Where $X_{i}$ and $X_{j}$ represent the observation value in region $i$ and region $j ; W_{i j}$ is the spatial weights matrix; $\bar{X}$ is the mean value of observed values; $n$ is the number of samples.

The local spatial autocorrelation was used to reveal the similarity or correlation between the spatial and its neighborhood; it can identify hot spots and check the heterogeneity of data. LISA (Local Index of Spatial Autocorrelation) generally used to test the local spatial autocorrelation. The equation as follow:

$$
\operatorname{LISA}=\frac{X_{i}-\bar{X}}{\sum_{i=1}^{n}\left(X_{i}-\bar{X}\right) / \mathrm{n}} \sum_{j=1}^{n} W_{i j}\left(X_{j}-\bar{X}\right)
$$

where $X_{i}$ is the attribute values for the space unit $i$; $\bar{X}$ is the mean value $X_{i}$; $\mathrm{n}$ is the number of samples; $W_{i j}$ is the spatial weight matrix; $X_{j}$ is the attribute values for the space unit $j$.

\section{Spatial Interpolation Analysis of Housing Prices in Nanchang}

We interpolated the housing prices by kriging interpolation, it is builds on variogram theory and structural analysis method and base on spatial autocorrelation as well as make the unbiased optimal estimation of the regional variables within a limited area by using the structural of semivariable function. The equation is as follow:

$$
Z\left(S_{0}\right)=\sum_{i=1}^{n} \omega_{i} Z\left(S_{i}\right)
$$

where $Z\left(S_{0}\right)$ is the measured value for position $i$; $\omega_{i}$ is the weight coefficient for position $i$; $\mathrm{n}$ is the number of samples.

In order to reveal the spatial distribution of prices and its differentiation gradient better, a isogram of housing prices was drawn by using $500 \mathrm{RMB}$ per square meter as the price interval. Overlying it with the interpolation results, then we obtained the price spatial distribution pattern of residential district in Nanchang city, as show in Figure 3.

\section{RESUlts}

\section{A. Sample Characteristics}

The natural logarithm transformation results of the average prices shows that: The average value (9.0042) was very close to the median value (9.0215); the standard deviation (0.2531) and the skewness $(-0.2145)$ were all close to zero; the kurtosis (4.5206) was close to 3. All this mean the date of housing prices of all samples is normally distributed.

\section{B. Spatial Pattern of Residential District}

In the buffer analysis map (Figure 1), two kinds of characteristics were identified: 1) Residential district have a significant features of "shortcut" characteristics, $83.91 \%$ of total samples are agglomeration along the $0.5 \mathrm{~km}$ of major traffic lines buffer, 36.26\% of total samples are agglomeration along the $1 \mathrm{~km}$ of subway Line 1 buffer, especially newly-built residential community. 2) Residential district presents significant "hydrophilic" characteristics. $44.55 \%$ of the total samples are agglomeration along the $1 \mathrm{~km}$ of water buffer.

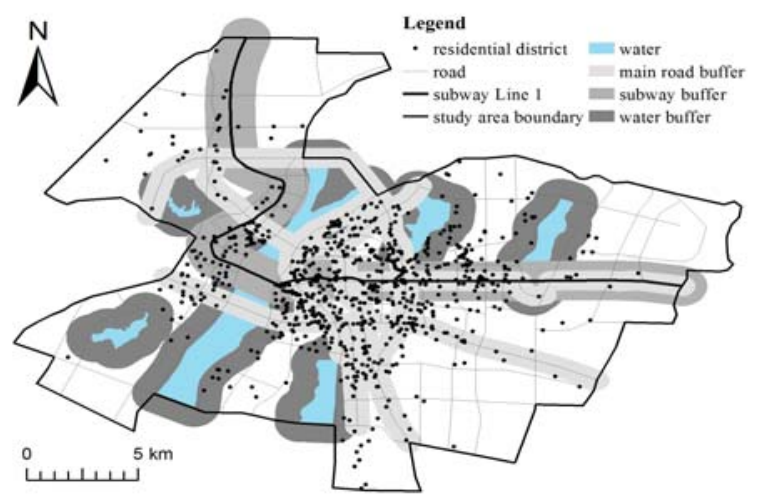

FIGURE I. BUFFER ANALYSIS OF REAL ESTATE DISTRIBUTION 


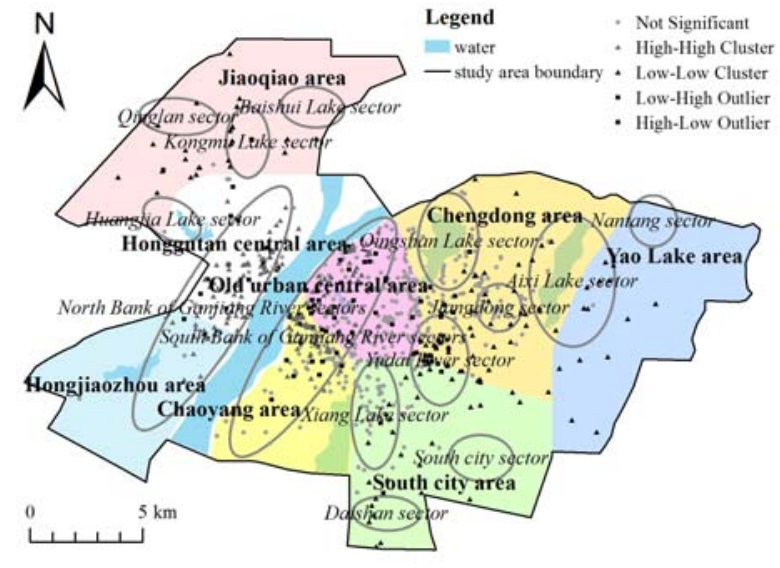

FIGURE II. LISA CLUSTER OF HOUSING PRICES

\section{Spatial Variations of Housing Prices}

According to the equation (1), we calculated the average price of all residential district samples in Nanchang. The Moran's I value is 0.06 , Given the z-score of 36.59 , which means $\mathrm{p}$ value is 0.01 , there is a less than $1 \%$ likelihood that this clustered pattern could be the result of random chance. It shows that there is a significant spatial autocorrelation in housing prices of residential district. The closer the distance is, the stronger the correlation between the housing prices, and the residential district was aggregated distribution. Similar housing prices residential district is centralized distribution.

Local spatial autocorrelation has five agglomeration types, among which, "High-High Cluster" and "Low-Low Cluster" indicate a significant positive spatial correlation, things are adjacently in space, while "High-Low Outlier" and "Low-High Outlier" indicate a negative spatial correlation, things are heterogeneity in space. The results are showed in the LISA cluster map (Figure 2). It indicates that housing prices in Nanchang shows mainly the "High-High Cluster", "Low-Low Cluster" and not significant types, housing prices have a significant positive spatial correlation.

Housing prices present a trend of progressively decrease from Ganjiang River to both sides. There are 156 "High-High Cluster" type samples, the mean value of those residential district and their neighborhood are higher than whole samples. They are distributed around the Ganjiang River housing estate sector. The south bank of Ganjiang River residential sector includes the old urban central area and the north of Chaoyang area. The old urban central area has a long history with density population and highly prosperous business. The north bank of Ganjiang River residential sector including the central area of Honggutan area and Hong jiaozhou area, they are newly developed urban area, and they have superior geographical condition with convenient transportation and preferential policy. There are 117 "Low-Low Cluster" type samples, the mean value of those residential district and their neighborhood are lower than whole samples. They are mainly distributed on the edge of the main city, economic development in these areas are relatively backward. There are more industrial distributions, smaller population density. They are mainly concentrated in Jiaoqiao area, Yao Lake area, South city area and Southeast of the Chengdong area. There are 24 "High-Low Outlier" type samples, the mean value of that residential district is higher than but their neighborhood is lower than whole samples. They are close to city center with convenient transportation, developed real estate and prosperous business. They are concentrated in Middle Hongdu Avenue, South Qingshan Lake Avenue, East Nanjing Road and West Jiefang Avenue. In addition, there are 64 "High-Low Outlier" type samples, the mean value of that residential district is lower than but their neighborhood is higher than whole samples. They are old unit compound or employee dormitory with outdated equipment and relatively bad environment.

\section{Spatial Structure of Housing Prices in Nanchang}

Kriging interpolation analysis results are shown in Figure 3 and the fitting model test results are shown in Table 1 . The Mean Standardized is close to 0, Root-Mean-Square is close to Root-Mean-Square prediction error, and Normalized Root Mean Square is close to 1. It turned out that the model is ideal.

Combined the traffic map and electronic map of Nanchang, the spatial distribution of the housing prices have the following characteristics: 1) Housing prices decrease from the center of the city (old urban center and the Honggutan new district) to the edge of the city. 2) Housing prices present a single center (Honggutan center area) and multiple sub-centers (Chaoyang area, Guanying Road in the northeast of Xiang Lake, West Jianshe Road and the east coast of Qingshan Lake) spatial distribution structure. House prices decrease from these areas to surrounding areas, it's relatively lower in Changbei economic and technological development zone and Qing Yunpu area. 3) The regional housing prices changes are obviously different. The housing prices in north shore of Ganjiang River are diminishing outwards in half concentric circles from Honggutan central area, and none obvious subentries here. While there are several sub-centers on the south shore of Ganjiang River, mainly appear in the vicinity of lakes. 4) Living environment has a significant impact on housing prices. Houses near lakes, rivers or wetlands have higher prices and they are hot spots of purchase.

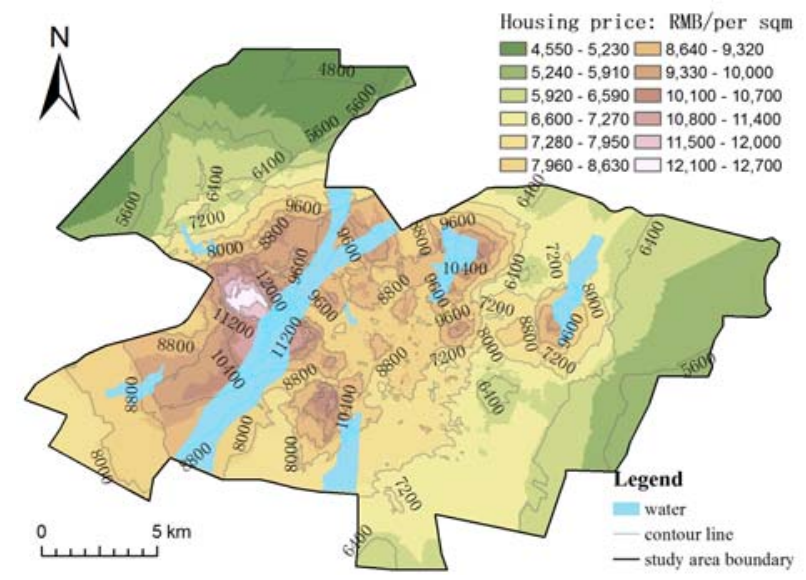

FIGURE III. SPATIAL INTERPOLATION OF HOUSING PRICES 
TABLE I. ACCURACY TEST OF KRIGING MODEL OF HOUSING PRICES

\begin{tabular}{|c|c|c|c|}
\hline Index & Value & Index & Value \\
\hline Average value & 5.634 & Root Mean Square & 1935.670 \\
\hline Mean Standardized & 0.002 & Mean Standard Error & 1867.800 \\
\hline $\begin{array}{c}\text { Normalized Root } \\
\text { Mean Square }\end{array}$ & 1.037 & & \\
\hline
\end{tabular}

\section{DISCUSSION AND CONCLUSIONS}

In this study we explored the residential district and housing prices spatial distribution in Nanchang, we found that residential district presents a characteristic of new urbanization and suburbanization, and significant feature of "shortcut" and "hydrophilic". The residential district in Nanchang shows a positive spatial correlation. The main agglomeration types of housing prices are "High-High Cluster", "Low-Low Cluster" and not significant types. Housing prices have a spatial distribution structure of single center and multiple sub-centers, which is obvious residential differentiation in space.

Specifically, our study found that residential district in Nanchang has a significant characteristic of new urbanization and suburbanization, and the feature of "shortcut" and "hydrophilic". Thus provides a typical case that traffic construction and natural environment have an important influence on residential space differentiation, especially the impact of lakes and rivers. Nanchang is a city with rich water resources, beautiful scenery around water greatly improve living comfort, therefore welcomed by real estate developers and residents. The urban residential space presents a residence differentiation phenomenon similar to other cities of China. For example, Y. Y. Su and his colleagues found the housing rental in Beijing is gradually declines from the city center to the suburb [15]. We found that housing prices show a spatial distribution structure of single center and multiple sub-centers, which is obvious differentiation in space distribution. Superior geographical location, traffic conditions and business forms make the highest housing prices in Honggutan center area. Which is consistent with previous literatures showing that housing prices has significant spatial autocorrelation. For instance, J. Q. Niu and her colleagues found that the spatial price of residential projects in Xi'an City presents the trend of a polarization structure to multi-core structure [16]. We found that trend of housing prices change is more obvious in the north shore than the south shore of Ganjiang River; there are more sub-centers in the south shore. Z. G. Liu and his colleagues found that Lanzhou urban residence spatial differentiation are different from the cities located on the east plains [17].

In summary, although the actual transaction prices and the prices on real estate network are not completely consistent, the spatial distribution of house prices still reveals well by using a variety of GIS spatial analysis methods. Our study enriches the case study of spatial structure of housing prices in mediumsized cities. Future research may benefit from identifying the spatial interaction effects of housing prices and investigate the impact of different drivers, especially some latest dynamic urban development planning, such as whether the newly constructed rail transit creates uplift to housing prices and identifying how uplift varies spatially.

\section{ACKNOWLEDGMENT}

This study was supported by the Natural Science Foundation of Jiangxi Province of China (No. 20133ACB2011) and the Graduate Innovation Fund Project of Jiangxi Provincial Education Development (YC2015-S118). We thank colleagues at Key laboratory of Poyang Lake Wetland and Watershed Research, Ministry of Education for assistance with data collection. We thank Dr Guibo SUN from the Chinese University of Hong Kong (CUHK) for his constructive comments and critical review of this paper.

\section{REFERENCES}

[1] L. Deng, Q. Shen and L. Wang, "Housing policy and finance in China: A literature review," US Department of Housing and Urban Development, 2009.

[2] Y. W. Chai, N. Ta and Z. D. Mao, "Urban Spatial Reconstruction in Cities in China: From the Perspective of Danwei," Modern Urban Research, vol. 3: pp. 5-9, 2011.

[3] Y. Wang, D. L. Wang and S. J. Wang, "Spatial Differentiation Patterns and Impact Factors of Housing Prices of China's Cities,” Scientia Geographica Sinica, vol. 33, pp.1157-1165, 2013.

[4] D. M. Brasington and D. Hite, "Demand for environmental quality: a spatial hedonic analysis,” Regional science and urban economics, vol. 35, pp. 57-82, 2005.

[5] T. Ogwang and B. Wang, "A hedonic price function for a northern BC community,” Social Indicators Research, vol. 61, pp.285-296, 2003.

[6] C. J. Olmo, "Prediction of housing location price by a multivariate spatial method: cokriging,” Journal of Real Estate Research, vol. 29, pp. 91-114, 2007.

[7] A. G. Can, "GIS and spatial analysis of housing and mortgage markets," Journal of Housing Research, vol. 9, pp. 61-86, 1998.

[8] B. D. Sun and Y. F. Wu, "Progress and prospect of residential spatial differentiantion of Chinese cities," City Planning Review, vol. 33, pp. 73-80, 2009.

[9] F. B. Shao and X. Zhang, "Research on residential prices influence factors analysis in Shanghai, based on hedonic model,” Economic Forum, pp. 9-13, 2008.

[10] X. Y. Ding, C. Hong, Z. Xiong and D. C. Nie, "Spatial Pattern of Housing Price in Changsha City Based on GIS,” Tropical Geography, vol. 32, pp. 423-428, 2012.

[11] F. Wang, X. L. Gao and B. Q. Yan, "Research on urban spatial structure in Beijing based on housing prices," Progress in Geography, vol. 33, pp. 1322-1331, 2014.

[12] P. A. Moran, "Notes on continuous stochastic phenomena," Biometrika, vol. 37, pp. 17-23, 1950.

[13] A. Getis and J. K. Ord, "The analysis of spatial association by use of distance statistics,” Geographical analysis, vol. 24, pp. 189-206, 1992.

[14] S. J. Zhu, F. Zhen, X. Qin and Y. Y. He, "Research on the Characteristics and Influence Mechanism of Second-hand Housing Activeness in Nanjing: Using Kernel Density Estimation,” Journal of Geo-Information Science, vol. 17, pp. 698-704, 2015.

[15] Y. Y. Su, D. L. Zhu and B. Geng, "The Spatial Structure and Affecting Factors of the Housing Rental in Beijing,” Economic Geography, vol. 34, pp. 64-69, 2014.

[16] J. Q. Niu, Y. Lv and K. W. Liu, “A study on the evolution of the residential spatial structure in Xi'an city from the perspective of urban planning,” Human Geography, vol. 26, pp. 48-53, 2011.

[17] Z. G. Liu and Z. B. Zhang, "Research of Lanzhou City’s urban residential differentiation,” Arid Land Geography, vol. 4, pp. 31, 2014. 